Tropical Journal of Pharmaceutical Research June 2010; 9 (3): 223-230

(C) Pharmacotherapy Group,

Faculty of Pharmacy, University of Benin

Benin City, 300001 Nigeria.

All rights reserved.

Research Article

Available online at http://www.tjpr.org

\title{
Wound Healing and Anti-oxidant Activities of the Fruit Pulp of Limonia Acidissima Linn (Rutaceae) in Rats
}

\author{
K llango ${ }^{1 *}$ and V Chitra ${ }^{2}$ \\ ${ }^{1}$ Departments of Pharmaceutical Chemistry and ${ }^{2}$ Pharmacology, SRM College of Pharmacy, SRM University, \\ Kattankulathur- 603 203. Tamilnadu, India.
}

\begin{abstract}
Purpose: The fruits of Limonia acidissima Linn are used traditionally in India for the treatment of tumours, asthma, wounds, cardiac debility and hepatitis. The purpose of the present study was to evaluate the wound healing activity of the methanol extract of its fruit pulp (MELA) in incision, excision and dead-space wound models.

Methods: Albino rats of either sex were divided into four groups, viz, wounded control, wounded rats administered standard drug, nitrofurazone (2\%), and wounded rats administered MELA 200 and 400 $\mathrm{mg} / \mathrm{kg}$, respectively. In incision wound model, wound breaking strength and epithelization period were evaluated, while in excision wound model, wound contraction was studied. In dead-space wound model, granulation tissue dry weight, hydroxyproline levels in dry granulation tissue, as well as superoxide dismutase (SOD) and catalase levels in wet granulation tissue were estimated. Granulation tissue was subjected to histopathological examination in order to determine whether there was healing by formation of collagen in the wound tissue in extract-treated animals.

Results: Increased wound breaking strength, decreased epithelization period, increased wound contraction, increased granulation tissue weight and hydroxyproline concentration were observed in the various groups, compared with the control group. Also, increased activity of anti-oxidant enzymes, i.e., higher SOD and catalase levels, were seen in extract-treated groups when compared to controls. Wound healing activity was statistically significant $(p<0.001)$ in animals treated with $400 \mathrm{mg} / \mathrm{kg}$ of the extract.

Conclusion: The methanol extract of $L$. acidissima possesses significant dose-dependant wound healing and anti-oxidant activities; this supports traditional claims for the plant as a wound healer.
\end{abstract}

Keywords: Limonia acidissima, Wound healing, Antioxidant enzymes, Wound models, Hydroxyproline. 


\section{INTRODUCTION}

Limonia acidissima Linn, syn. Feronia limonia (Rutaceae) is a moderate-sized deciduous tree grown throughout India. The fruits are woody, rough and used as a substitute for bael in diarrheoa and dysentery [1]. The bark and leaves of the plant are used for vitiated conditions of vata and pita while the fruits are used for tumours, asthma, wounds, cardiac debility and hepatitis [2]. The fruit contains flavanoids, glycosides, saponins and tannins [3]. Some coumarins [4, 5] and tyramine derivatives [6] have also been isolated from the fruits of Limonia. The leaves were reported to possess hepatoprotective activity [7] while the fruit shells contain antifungal compounds, namely, psoralene, xanthotoxin, 2, 6-dimethoxybenzoquinone and osthenol [8]. The stem bark of the plant has yielded (-)(2S)-5,3'-dihydroxy-4'-methoxy-6",6"dimethyl chromeno-(7,8,2",3")-flavanone along with several known compounds, including an alkaloid, five coumarins, a flavanone, a lignan, three sterols and a triterpene, which were found to possess antimicrobial activity [9].

The process of wound-healing involves inflammation, cell proliferation and contraction of collagen lattice formation [10]. When wound occurs, it is accompanied (within a short time) by pain, reddening and oedema, which are the classical symptoms of inflammation. These symptoms are caused by the release of eicosanoids, prostaglandins, leukotrienes and reactive oxygen species (ROS). ROS is produced in high amounts at the site of wound as a defense mechanism against invading bacteria. At the same time, the process of wound healing may be hampered in the presence of free radicals (which can damage wound surrounding cells) or by microbial infection [11]. Hence, this study was undertaken to evaluate the wound healing and antioxidant activities of the methanol extract of Limonia acidissima in experimentally-induced wound in rats.

\section{EXPERIMENTAL}

\section{Plant material}

The ripe fruits of Limonia acidissima were purchased from a local market in Chennai, India, during the month of August 2008 and separated into pulp and shell .The plant was authenticated by Prof. P Jayaraman, a taxonomist at Plant Anatomy Research Centre (PARC), Tambaram, Chennai, India. A voucher specimen (no. SRMCP/07/08) has been deposited in the Department of Pharmacognosy, SRM College of Pharmacy for future reference. The fruit pulp was shade-dried, coarsely powdered using a cutter mill and stored in an air-tight, lightresistant container for further use.

\section{Extraction}

The fruit pulp powder was defatted with hexane using a Soxhlet apparatus. The defatted marc was further Soxhlet-extracted with methanol and the extract obtained was concentrated using a rotary flash evaporator. The extract yield was $23 \% \mathrm{w} / \mathrm{w}$ on dry weight basis, and it was stored in a vacuum desiccator for pharmacological evaluation.

\section{Drug formulation}

The extract $(0.5 \mathrm{~g})$ was mixed with $9.5 \mathrm{~g}$ of simple ointment in a porcelain tile and transferred to a tightly-closed amber coloured container. Two types of drug formulations were prepared: For topical administration, 5\% $\mathrm{w} / \mathrm{w}$ ointment was prepared in simple ointment Base I.P. For oral administration, 200 and $400 \mathrm{mg} / \mathrm{kg}$ suspensions of the extract was prepared in corn oil for administration orally by intragastric tube.

\section{Animals}

Inbred adult male Wistar albino rats (150 $200 \mathrm{~g}$ ) and albino mice were obtained from the animal house of SRM College of Pharmacy. The animals were maintained in a well- ventilated room at a temperature of 
$25 \pm 1^{\circ} \mathrm{C}$ with $12: 12$ hour light/dark cycle in polypropylene cages. Standard pellet feed (Hindustan Lever, Bangalore) and tap water was provided ad libitum throughout the experimentation period. The animals were acclimatized to laboratory conditions for 10 days prior to initiation of experiments. The project proposal was approvedby the Institutional Animal Ethical Committee (ref. no. IAEC/33/2007).

\section{Acute toxicity studies}

Acute oral toxicity of the extract was determined using nulliparous, non-pregnant female mice. The mice $(n=6)$ were fasted for $3 \mathrm{~h}$ prior to the experiment, administered a single dose of the extract in water and observed for mortality up to the 48th hour. Based on the short term toxicity studies, the dose of the test animals were determined as per OECD guidelines 423 [12]. All the animals were observed for lethal or toxic signs after giving doses of up to $2000 \mathrm{mg} / \mathrm{kg}$. Healthy rats $(n=6)$ were orally fed with increasing doses $(5 \mathrm{mg} / \mathrm{kg}$ to $2 \mathrm{~g} / \mathrm{kg}$ ) of the extract for 14 days. Doses up to $2 \mathrm{~g} / \mathrm{kg}$ body weight did not produce any toxicity and mortality. Of the maximum tolerated doses, 10 and $20 \%$ were selected for the study.

\section{Wound healing activity}

For assessment of wound healing activity, excision, incision and dead space wound models were used. The animals were divided into nine groups of 6 animals each, with three groups each used for excision, incision and dead space wound models, respectively.

In the incision wound model, Group I (control) was untreated (control). Group II (reference standard) received topical application of 2 $\%$ w/w nitrofurazone cream twice a day for 21 days, while Group III (test) received topical application of $5 \%$ w/w of the extract in Simple Ointment I.P. twice a day for both excision and incision models for 21 days. In the excision wound model [13], Group I served as control (corn oil, $1 \mathrm{ml} / \mathrm{kg}$, topically).
Groups II and III received topical doses of 200 and $400 \mathrm{mg} / \mathrm{kg}$ of the extract, respectively, for 21 days. The animals were anaesthetized under light ether anesthesia and then the skin of the impressed area was excised to full thickness to obtain a wound area of about $500 \mathrm{~mm}^{2}$. The drugs were topically applied once a day until complete epithelization. The parameters studied were wound closure (measured at regular intervals of time to determine percent wound closure) and epithelization time (indicated by the formation of new epithelial tissue to cover the wound). Percent wound closure was recorded on days $4,8,12,16,20$ and 21 until complete re-epithelialization was achieved. The day the scar peeled off without leaving any residual raw wound was considered the day complete epithelialization was attained.

In the incision model [14], the rats were anaesthetized by anesthetic ether and two longitudinal paravertibral incisions of $6 \mathrm{~cm}$ length were made through the skin and cutaneous muscle at a distance of about 1.5 $\mathrm{cm}$ from the midline on each side of the depilated back. After the incision, the parted skin was sutured $1 \mathrm{~cm}$ apart using surgical thread (no. 000) and curved needle (no. 11). The wounds were left undressed. The drugs were topically applied to the wound once a day until complete healing occurred. The sutures were removed on the 8th (postwound) day. .

\section{Determination of wound breaking strength}

The skin breaking strength of the 10-day old wound was measured by the method of Lee et al [15). The rats were secured to the operating table and a line was drawn on either side of the wound $3 \mathrm{~mm}$ away from the wound. Two Allice forceps were firmly applied to the line facing each other. One of the forceps was fixed, while the other was connected to a freely suspended lightweight polypropylene graduated container through a string run over to a pulley. Water was allowed to flow from the reservoir slowly and steadily into the container. A gradual increase in 
weight was transmitted to the wound site pulling apart the wound edges. The moment the wound just opened up, the water flow was arrested and the volume of water collected in the container (approximately equal to its weight) was noted. Three readings were recorded for a given incision wound and the procedure was repeated on the wound on the contra lateral side. The mean reading of the group was taken as the breaking strength for a given group.

Dead space wounds were created by implanting two pre-weighed sterilized polypropylene tube (2.5 length $\times 0.25 \mathrm{~cm}$ diameter) beneath the dorsal para-vertebral skin of the anaesthetized rats. The animals were divided into three groups of six animals each. Group I served as control and the animals received the vehicle for 10 days. Group II (test group) had the wound treated with the extract $(200 \mathrm{mg} / \mathrm{kg})$ for 10 days. Group III (test group) wound was treated with the extract $(400 \mathrm{mg} / \mathrm{kg})$ for 10 days.

On the $10^{\text {th }}$ (post-wound) day, the granulation tissues formed on the implanted tubes were carefully detached from surfaces of the tubes. The wet weight of the granulation tissue was noted. The breaking strength of granulation tissue was measured by the method of Lee et al [15]. Thereafter, the granulation tissues were collected, dried at $60^{\circ} \mathrm{C}$ for $24 \mathrm{~h}$ and their dry weights were noted. The dried tissue was added to $5 \mathrm{ml} 6 \mathrm{M} \mathrm{HCl}$ and kept at $110^{\circ}$ $\mathrm{C}$ for $24 \mathrm{~h}$. The neutralized acid hydrolysate of the dry tissue was used for the determination of hydroxyproline [16]. Granulation tissue from the second tube was collected in phosphate-buffered saline for the estimation of antioxidant enzymes superoxide dismutase (SOD) [17] and catalase [18], while a piece of the wet granulation tissue was preserved in $10 \%$ formalin for histological studies.

\section{Estimation of hydroxyproline [16]}

Dry granulation tissue from both control and test groups were used for the estimation of hydroxylproline. Hydroxyproline present in the neutralized acid hydrolysate was oxidized by sodium peroxide in presence of copper sulfate, and subsequently complexed with $p$ dimethylaminobenzaldehyde to develop a pink colour that was measured spectrophotometrically at $540 \mathrm{~nm}$.

\section{Histopathological evaluation of wounded tissues}

A portion of the granulation tissue was subjected to histopathological studies. The tissues were fixed in 10\% neutral formalin solution for $24 \mathrm{~h}$ and dehydrated with a sequence of ethanol-xylene solution series [19]. The materials were filtered and embedded with paraffin $\left(40-60^{\circ} \mathrm{C}\right)$ and microtome sections of $5 \mu$ thickness taken. The sections were again processed with ethanol-xylene solvent series and stained with hemotoxylin-eosin dye. The histopathological changes observed were photographed using a compound light microscope (Novex, USA)

\section{Statistical analysis}

The results were expressed as mean \pm SEM of 6 animals in each group. The data were statistically evaluated by one-way ANOVA, followed by Dunnet's t-test for comparison of test groups with control. Values of $p<0.05$ were considered statistically significant.

\section{RESULTS}

The methanol extract of the fruit pulp of $L$. acidissima was non-toxic up to a dose of $2000 \mathrm{mg} / \mathrm{kg}$. Therefore, 10 and $20 \%$ of this dose was selected for the evaluation of wound healing activity.

\section{Wound healing activity}

In the excision wound model, as shown in Table 1, the wound contracted progressively when treated with the extracts and the 
reference drug and required a mean period of $16.0 \pm 0.8$ days for optimum healing as evidenced by the shorter period required for eschar dropping. Thus the extracts promoted wound contraction significantly when compared with the control group.

The wounding healing results for the incision and dead space models are indicated in Table 2. Breaking strength, hydroxyproline, granulation tissue weight, as well as SOD and catalase all increased significantly $(p<$ $0.05)$, following treatment with the extract and standard drug, when compared with the control group. Thus, the extract not only promoted wound healing but also exerted anti-oxidant activity.

\section{Histopathological evaluation}

The photomicrographs of the granulation tissues obtained from the animal wounds are shown in Fig 1. The images revealed that while increased number of fibroblasts can be

Table 1: Effect of $\boldsymbol{L}$. acidissima on wound contraction and epithelialization period (Excision model)

\begin{tabular}{|c|c|c|c|c|c|c|c|}
\hline \multicolumn{8}{|c|}{ Wound contraction (\%) } \\
\hline Treatment & Day 0 & Day 4 & Day 8 & Day 12 & Day 16 & Day 21 & $\begin{array}{l}\text { Epithelialization } \\
\text { period (day) }\end{array}$ \\
\hline Control & $12.5 \pm 2.6$ & $22.4 \pm 2.8$ & $42.4 \pm 1.2$ & $57.2 \pm 0.6$ & $67.4 \pm 0.5$ & $85.8 \pm 0.7$ & $20.0 \pm 0.9$ \\
\hline Standard & $21.5 \pm 1.5$ & $36.0 \pm 0.7$ & $63.6 \pm 1.0$ & $78.8 \pm 0.4$ & $92 \pm 0.6^{\star * *}$ & $100 \pm 0$ *** & $15.0 \pm 0.06^{* * *}$ \\
\hline $\begin{array}{l}\text { Extract } \\
(200 \mathrm{mg} / \mathrm{kg})\end{array}$ & $12 \pm 0.44$ & $23.5 \pm 0.8$ & $48.5 \pm 0.5$ & $60.2 \pm 0.8$ & $75.7 \pm 0.4$ & $89.8 \pm 0.5$ & $18.0 \pm 0.4$ \\
\hline $\begin{array}{l}\text { Extract } \\
(400 \mathrm{mg} / \mathrm{kg})\end{array}$ & $14 \pm 0.45$ & $23 \pm 0.54$ & $45.2 \pm 0.8$ & $70.7 \pm 0.5$ & $89.8 \pm 0.6^{* *}$ & $98.8 \pm 0.3^{* * *}$ & $16.6 \pm 0.3^{* *}$ \\
\hline
\end{tabular}

Values are mean $\pm \operatorname{SEM}(n=6) ;{ }^{*} P<0.05 ;{ }^{* *} P<0.01 ;{ }^{* * *} p<0.001$ (when compared with wounded control and standard group)

Table 2: Effect of L.acidissima extract on incision and dead space wound models, and antioxidant enzymes

\begin{tabular}{lcllll}
\hline Treatment & $\begin{array}{c}\text { Breaking } \\
\text { strength } \\
(\mathbf{g})\end{array}$ & $\begin{array}{c}\text { Hydroxyproline } \\
\mathbf{m g} / \mathbf{g} \text { tissue }\end{array}$ & $\begin{array}{l}\text { Dry tissue } \\
\text { weight } \\
\text { (mg/100g rat) }\end{array}$ & $\begin{array}{l}\text { SOD } \\
\text { U/mg protein }\end{array}$ & $\begin{array}{l}\text { Catalase } \\
\text { U/mg protein }\end{array}$ \\
\hline $\begin{array}{l}\text { Control } \\
\text { Standard }\end{array}$ & $275.1 \pm 22.9$ & $15.5 \pm 0.5$ & $30.5 \pm 0.2$ & $1.8 \pm 0.5$ & $0.01 \pm 0.018$ \\
$\begin{array}{l}\text { Extract } \\
(200 \mathrm{mg} / \mathrm{kg})\end{array}$ & $380.0 \pm 18.5^{\star *}$ & $55.2 \pm 0.3$ & $\mathrm{Nil}$ & $\mathrm{Nil}$ & - \\
& & & $44.6 \pm 0.3$ & $4.9 \pm 0.8$ & $0.43 \pm 0.01$ \\
$\begin{array}{l}\text { Extract } \\
(400 \mathrm{mg} / \mathrm{kg})\end{array}$ & $418.0 \pm 16.5^{* *}$ & $67.4 \pm 0.3$ & & & \\
\hline
\end{tabular}

Values are mean $\operatorname{SEM}(n=6) ;{ }^{*} P<0.05 ;{ }^{* *} P<0.01 ;{ }^{* *} P<0.001$ (when compared with groups I and II); * significant; ${ }^{* *}$ more significant; ${ }^{* *}$ highly significant; nil = no separate standard group for dead space in SOD = superoxide dismutase; the model

seen in animals in the control group, the collagen fibres are indistinguishable. On the other hand, animals treated with $200 \mathrm{mg} / \mathrm{kg}$ of the extract showed moderate collagenation 
and fibrosis. Animals treated with $400 \mathrm{mg} / \mathrm{kg}$ of the extract revealed even higher fibrosis and well-formed collagen fibres.
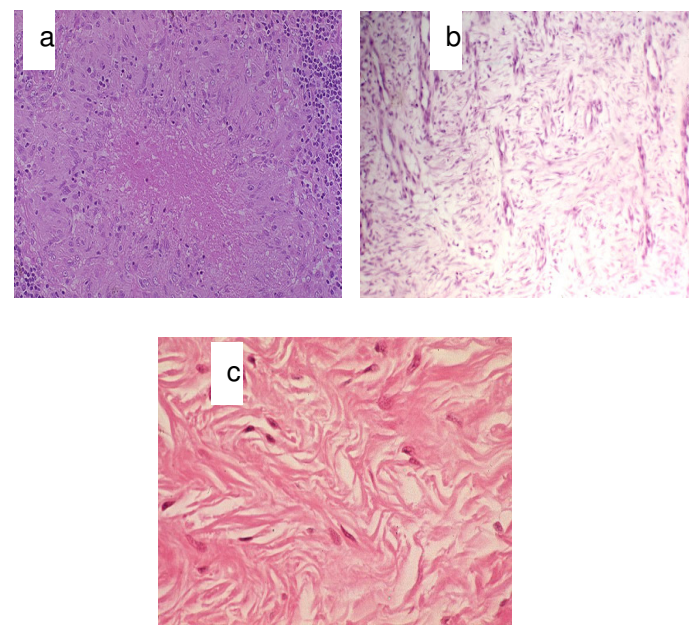

Figure 1: Histopathology of granulation tissue (a) Control animals, showing increased number of fibroblasts and indistinguishable collagen fibres; (b) L. acidissima extract-treated (200 mg/kg) animals, showing moderate collagenation and fibrosis; and (c) L. acidissima extract-treated (400 $\mathrm{mg} / \mathrm{kg}$ ) animals, showing a high level of fibrosis as well as well-formed collagen fibres

\section{DISCUSSION}

Wound healing or repair is a natural process of regenerating dermal and epidermal tissue, and may be categorized into three phases, viz, inflammation, proliferation and remodelling phase. In the inflammation phase, various growth factors such as tumour necrosis factor (TNF), interleukins (IL) are released to initiate the proliferation phase. The latter is characterized by angiogenesis, collagen deposition, granular tissue formation, epithelialization and wound contraction [20]. In the last phase, the levels of collagen production and degradation equalize, after which disorganized fibres are rearranged thus increasing the tensile strength of the wound [21]. The capacity of wound to heal depends, in part, on its depth, as well as on the overall health and nutritional status of the individual. Following injury, inflammatory response occurs and the cells below the dermis begin to increase collagen production. Later, the epithelial tissue is regenerated. It is well known that stages in healing, namely, coagulation, inflammation, microphasia, fibroblasts formation and collagenation, are intimately interlinked [22]. The process of wound contraction and epithelization is separate and independent. The activity of fibroblast is responsible for wound contraction and involves movement of entire dermis. Epithelization involves migration and proliferation of cells. It is known that stabilization of lysosomal membranes, inhibition of cellular migration and inhibition of fibroblast contraction are responsible for their anti-healing effects [23]. Thus, intervention in any one of these phases by drugs would eventually lead to either promotion or depression of collagenation, wound contraction and epithelization [24].

In the present investigation, the methanol extract of $L$. acidissima at the doses of 200 and $400 \quad \mathrm{mg} / \mathrm{kg}$ showed significantly increased healing by wound contraction, when compared to the control group. Increase in the breaking strength of the wound is indicative of improved collagenation which contributes to healing, enhances epithelization and promotes wound contraction by increasing granulation tissue weight due to infiltration of macrophages [25].

Collagen is a major protein of the extracellular matrix and is the component that ultimately contributes to wound strength. Breakdown of collagen liberates free hydroxyproline and its peptide. Therefore, measurement of hydroxyproline could be used as an index for determining collagen turnover [26]. The extract-treated groups showed significant increases in the level of hydroxyproline, which is a reflection of increased collagen content. This was confirmed by histopathological examination of wound granulation tissue which showed a well-developed matrix in extract-treated groups with the collagen was well-organized 
and bundles formed between the cells. There was also better neovascularisation in the extract-treated groups than in the wounded control groups.

Reactive oxygen species (ROS) play a vital role in wound healing and can trigger various beneficial oxygen free radicals. ROS also play an important role in the failure of ischaemic wound healing while antioxidants improve healing in ischaemic skin wounds [27]. Elevated lipid peroxide levels have also been demonstrated in certain inflammatory skin lesions such as wound and dermatitis [28]. Therefore, if a compound has antioxidant potential, it can be a good therapeutic agent for enhancing the wound healing process [29]. An increase in the levels of anti-oxidant enzymes (SOD and catalase) was observed in the granulation tissue of the extract-treated groups may also have contributed to the wound healing effect of the extract.

\section{CONCLUSION}

The present study indicates the wound healing and antioxidant activities of $L$. acidissima in experimental animal using incision, excision and dead space wound models. Further studies are going on in our laboratory to isolate and identify the active principles responsible for the wound healing and antioxidant activities of this extract.

\section{ACKNOWLEDGEMENT}

The authors are grateful to Dr R Shivakumar, Pro-Vice Chancellor, SRM University and Dr KS Lakshmi, Dean, College of Pharmacy, SRM University, Kattankulathur, for providing facilities to carry out this work.

\section{REFERENCES}

1. Anonymous, The Wealth of India: A Dictionary of Indian Raw Materials and Industrial Products, IV volume series. Publications \& Information Directorate (CSIR), New Delhi, 1995. p. 19.
2. Kirtikar KR, Basu BD. Indian Medicinal Plants. Dehradun, India, International Book Distributors, 2005, Vol l, pp. 478-79.

3. Saima Y, Das AK, Sarkar KK, Sen AK, Sur P. An antitumor pectic polysaccharide from Feronia limonia,Int.J.Biol.Macromol, 2000; 27: 333335.

4. Ghosh $P$, Sil $P$, Majumdar SG, Thakur $S A$ Coumarin from Limonia acidissima, Phytochemistry, 1982; 21: 240-241.

5. Chatterjee A, Sankar S, Shoolery JN. 7-Phenyl acetoxy Coumarin from Limonia crenulata Phytochemistry, 1980; 19: 2219-2220.

6. Parthasarathi G, Prabal S, Srabani D, Swapnadip T, Kokke WCMC, Akihisa T, Shimizu $N$,Tamura T, Matsumoto T. Tyramine Derivatives from the Fruit of Limonia acidissima. .J. Nat. Prod, 1991; 54: 1389 1393.

7. Kamat $C D$, Khandelwal KR, Bodhankar SL, Ambawade SD, Mhetre NA. Hepatoprotective activity of leaves of Feronia elephantum Correa (Rutaceae) against $\mathrm{Ccl}_{4}$ - induced liver damage in rats. J.Natural Remedies, 2003; 3: 148-154.

8. Adikaram NKB, Yamuna $A$, Lesliegunatilaka $A$, Ratnayuke Bandara BM, Kithsiri EM Wijeratne. Antifungal activity, acid and sugar content in wood apple (Limonia acidissima) and their relation to fungal development. Plant pathology, 2007; 38: 258-265.

9. Rahman MM, Gray Al. Antimicrobial constituents from stem bark of Feronia limonia, Phytochemistry, 2001; 59: 73 - 77.

10. Sidhu GS, Mani H, Gaddipatti JP, Singh AK, Seth $P$, Banaudha KK, Patnaik GK Maheshwari RK. Curcumin enhances wound healing in streptozotocin induced diabetic rats and genetically diabetic mice. Wound Repair and Regeneration, 1999; 7:362-374.

11. Houghton PJ, Hylands PJ, Mensahb AY, Hensel A, Deters AM. In vitro tests and ethnopharmacological investigations: wound healing as an example. J. Ethnopharmacol, 2005; 100: 100 107.

12. OECD (2001) Test Guideline 423. OECD Guideline for Testing of Chemicals. Acute Oral ToxicityAcute Toxic Class. http://www.oecd.org/ document.

13. Morton JP, Malone MH. Evaluation of vulnerary activity by open wound procedure in rats. Arch Int Pharmacodyn, 1972; 196: 117-120.

14. Ehrlich HP, Hunt TK. The effect of cortisone and anabolic steroids on the tensile strength of healing wounds. Ann Surg, 1968; 167: 117.

15. Lee $\mathrm{KH}$. Studies on the mechanism of action of salicylates II. Effect of vitamin $A$ on wound healing retardation of aspirin. J.Pharmacol Sci, 1968; 57: 1238-1240.

16. Neumann RE, Logan MA. The determination of collagen and elastin in tissues. J.Biochem, 1972; 186: 549-556. 
17. Poonam K, Ballabh D, Vishwanathan PN. A modified spectrophotometric assay of superoxide dismutase. Indian $J$ Biochem Biophysics, 1984; 21: 130-32.

18. Aebi HE. Methods of Enzymatic Analysis 1974 3rd New York Academic Press III: pp. 273-84.

19. Mukherjee. KL Medical Laboratory Technology. New Delhi: Tata McGraw-Hill Ltd, 2000.

20. Chang $H Y$, Sneddon JB, Alizadeh $A A$, Sood $R$ ,West RB, Montgomery K, Chi JT, Van de Rijn $M$, Botsein D, Brown PO. Gene expression signature of fibroblasts serum response predicts human cancer progression: similarities between tumors and wounds. PLoS Biol. 2004 Feb; 2(2):E7.

21. Smith R. Recovery and tissue repair. British Medical Bulletin, 1985; 41(3): 295-301.

22. Nayak BS, Suresh Rao AVC, Pillai GK, Davis EM, Ramkissoon V, McAre A. Evaluation of wound healing activity of Vandarox burghii R.Br (Orchidacea) - A preclinical study in rat model. Int J Low Extrem Wounds, 2005; 4: 200-4.

23. Nayak BS, Isitor GN, Maxwell A, Bhogadi V, Ramdath DD. Wound healing activity of Morinda citrifolia fruit juice on diabetes induced rats. J Wound Care, 2007 Feb; 16(2): 83-6.
24. Bigoniya $P$, Rana AC. Wound healing activity of Euphorbia nerifolia leaf ethanolic extract in rats. Indian J Nat Remedies, 2007; 7: 94-101.

25. Michel JW and Fredrickson JW. Wound healingoxygen free radicals and wound healing. Clin Plast Surg, 1990; 17: 1473-83.

26. Shetty, S.; Udupa, S.; Udupa, L.; Somayaji, N. Wound healing activity of Ocimum sanctum Linn. With supportive role of antioxidant enzymes. Indian J Physiol Pharmacol, 2006; 50(2): 163-168.

27. Senel O, Ozabay $D$, Bulan R. Oxygen free radicals impair healing in ischemic rat skin Ann Plast Surq, 1997; 39: 516-19.

28. Niwa, Y., Kanoh $T$, Sakane $T$, Soh H, Kawai S, Miyachi $Y$. The ratio of lipid peroxides to superoxide dismutase activity in the skin lesions of patients with severe skin disease: an accurate prognostic indicator. Life Sci, 1987; 40: 921-927.

29. Udupa AL, Kulkarni DR, Udupa SL. Effect of Tridax procumbans extracts on wound healing. Int $J$ Pharmacog, 1995; 33:37-40. 